\title{
The first evidence of Middle Palaeolithic Nubian technology in north-central Oman
}

\author{
A. Beshkani ${ }^{1, *}$, T. Beuzen-Waller ${ }^{2}$, S. Bonilauri ${ }^{3} \&$ G. Gernez ${ }^{4}$
}

Since 2012, the French Mission in Oman has discovered several Palaeolithic sites in the south-eastern foothills of the Sufrat Dishshah (a hill of the Sufrat Valley/Wādī al-Cufrāt), in the Adam region of north-central Oman. These sites are attributed to the Lower through to the Late Palaeolithic (Bonilauri et al. 2015). The 2016 field season was dedicated to further investigation of the previously identified sites of the Sufrat Dishshah area. A number of additional artefacts were located and studied on site; four artefacts - two bifaces and two Nubian cores-were retained for further study. These finds have particular importance for the understanding of Middle Palaeolithic variability and cultural diffusion in Oman, and they represent one of the most significant results of the 2016 Adam expedition.

The Nubian Complex, a subcategory of the Levallois technocomplex, was first identified in northern Sudan in the 1960s (Guichard \& Guichard 1965). To date, additional sites using this technology have been discovered in North Africa-the middle and lower Nile Valley_and also East Africa (Van Peer 2000; Van Peer et al. 2010). Outside of the African continent, Nubian technology has been identified across southern Arabia, including central Yemen (Inizan \& Ortlieb 1987; Crassard 2009) and southern Oman (Rose et al. 2011; Usik et al. 2012), and in northern Saudi Arabia at the Al-Jawf sites (Hilbert et al. in press). The Nubian Complex emerged chronologically in early MIS 5 (Vermeersch 2010). In southern Oman, the site at Aybut Al Auwal places the Arabian Nubian Complex at 106000 years ago (Rose et al. 2011) (Figure 1).

The Nubian Complex is generally divided into types one and two. In the former, management of the medial distal guiding ridge on the flaking face is usually achieved by removing two distal-divergent débordant flakes to form the pointed distal end through the negative of the bulb of percussion. In most cases, a convergent final product was removed from the opposed striking platform at the proximal end. Both of the cores collected from the Sufrat site-Adam region (Figure 2)—show this specific bidirectional flaking pattern with lateral preparation. As such, the cores can be attributed to the Nubian type one.

1 Paris Ouest Nanterre La Défense University, UMR 7041-ArScan, AnTET Maison de l'Archéologie et de l'Ethnologie, 21 allée de l'Université, 92023 Nanterre Cedex, France

2 Paris-Sorbonne University, UMR 8185 ENeC-Espaces, Nature et Culture, France (Email: tara.beuzen@gmail.com)

3 CNRS UMR 7194-Histoire Naturelle de l'Homme Préhistorique, Département de Préhistoire, Musée de l'Homme, 17 place du Trocadéro, 75016 Paris, France (Email: stephanie.bonilauri@gmail.com)

4 MCF Paris-Sorbonne University, UMR 7041-ArScan, VEPMO, 21 allée de l'Université, 92023 Nanterre Cedex, France (Email: guillaume.gernez@gmail.com)

* Author for correspondence (Email: a.beshkani@gmail.com)

(C) Antiquity Publications Ltd, 2017 ANTIQUITY 91 356, e1 (2017): 1-5 


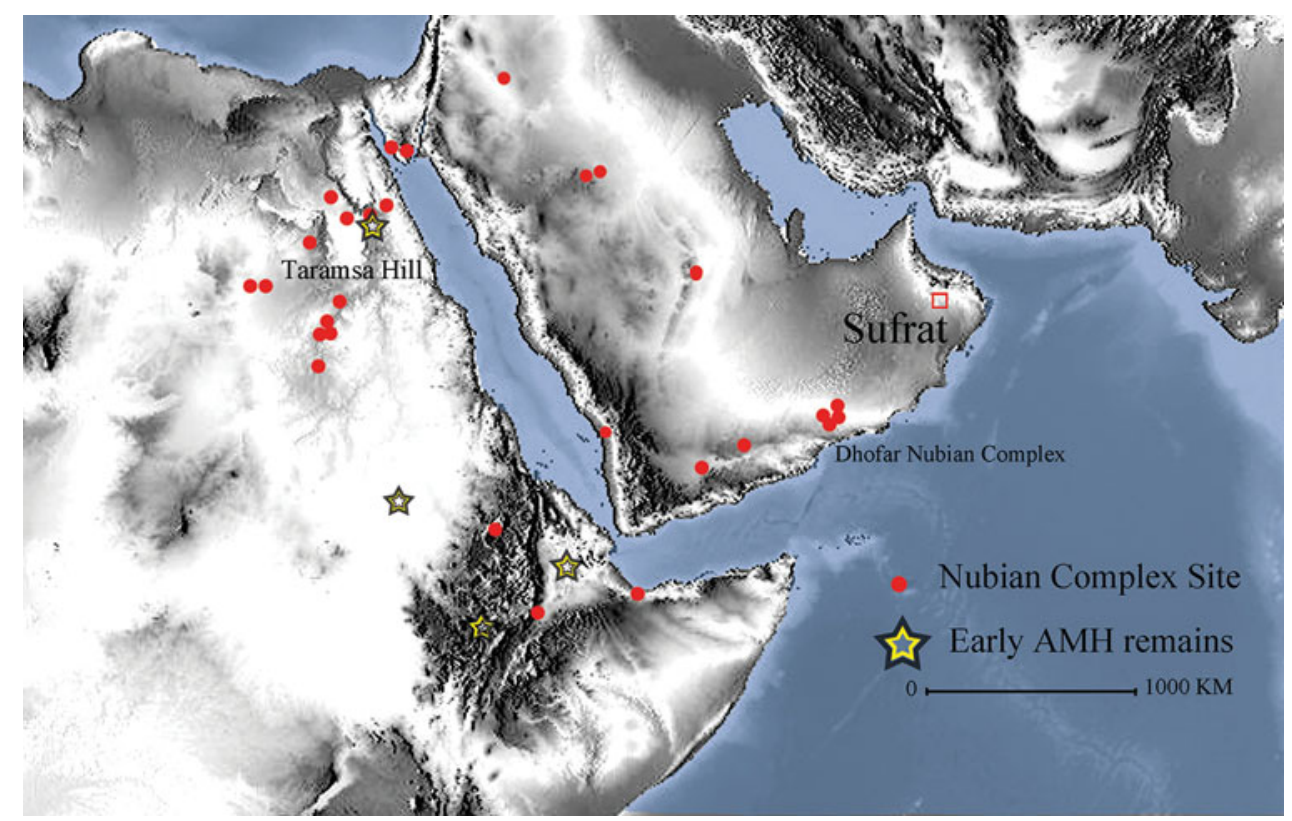

Figure 1. Map of Nubian Complex occurrences in north-eastern Africa and Arabia.

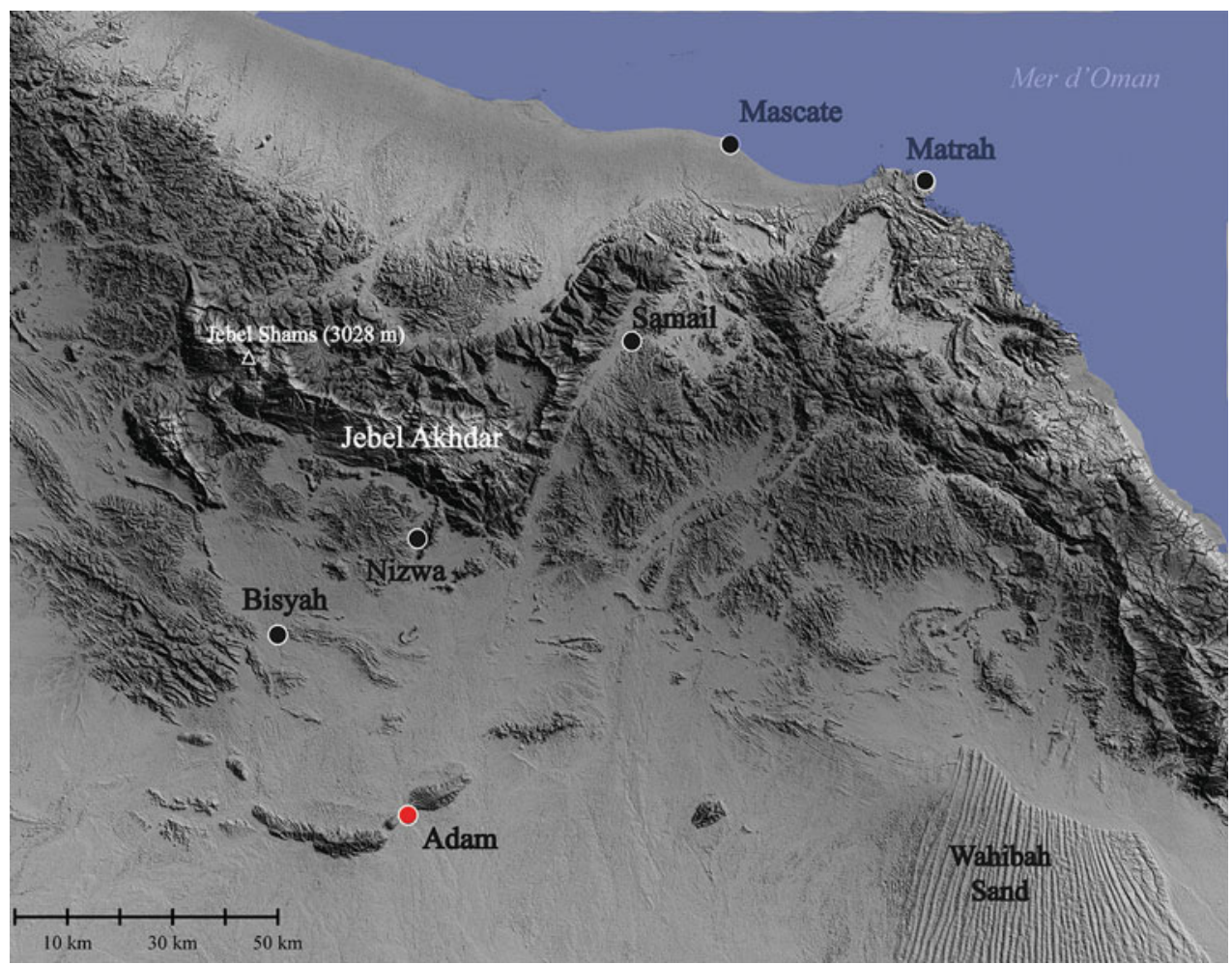

Figure 2. Map of the study region in Ad Dakhiliyah Governorate.

(C) Antiquity Publications Ltd, 2017 

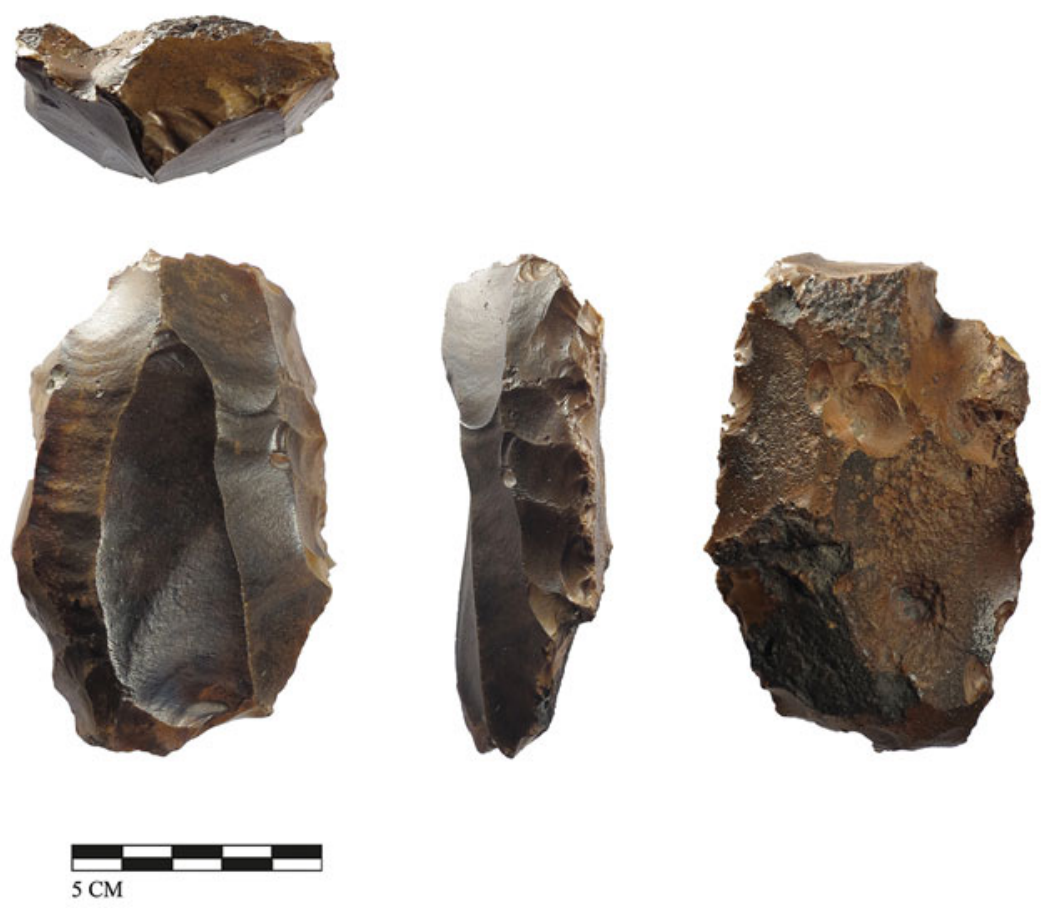

Figure 3. Nubian type one core from Sufrat Dishsha.

Our preliminary studies indicate that the Nubian Complex, although present, illustrates a minority of the artefact-production methods in use at the Sufrat sites. It should be noted that other Levallois-production methods, such as preferential and recurrent cores, were identified during earlier prospection at Sufrat (Bonilauri et al. 2015).

The Sufrat Nubian cores are smaller and differ in appearance from the classic forms reported from the Dhofar Nubian Complex (Figure 3), although, among the Nubian sites in the Dhofar region, the cores from locality TH.69 are smaller than from other typical Nubian sites (Usik et al. 2012). Given their size and technological characteristics, the Sufrat Nubian cores are most similar in terms of reduction strategy and method to the Late Dhofar Nubian complex of the Mudayy area, but it is uncertain whether the Sufrat material represents a local industry derived from classic Nubian Levallois technology (Figure 4).

Prior to our reassessment of the Sufrat site and the discovery of these cores, it was believed that the Nubian Complex did not extend farther east than the Dhofar region in southern Oman; hence, this is the first evidence of Nubian technology in the north of the country. In turn, this discovery will help to refine our understanding of the Middle Palaeolithic chronology and variability of Oman. We hope to continue our research in this region with further prospection. 


\section{A. Beshkani et al.}
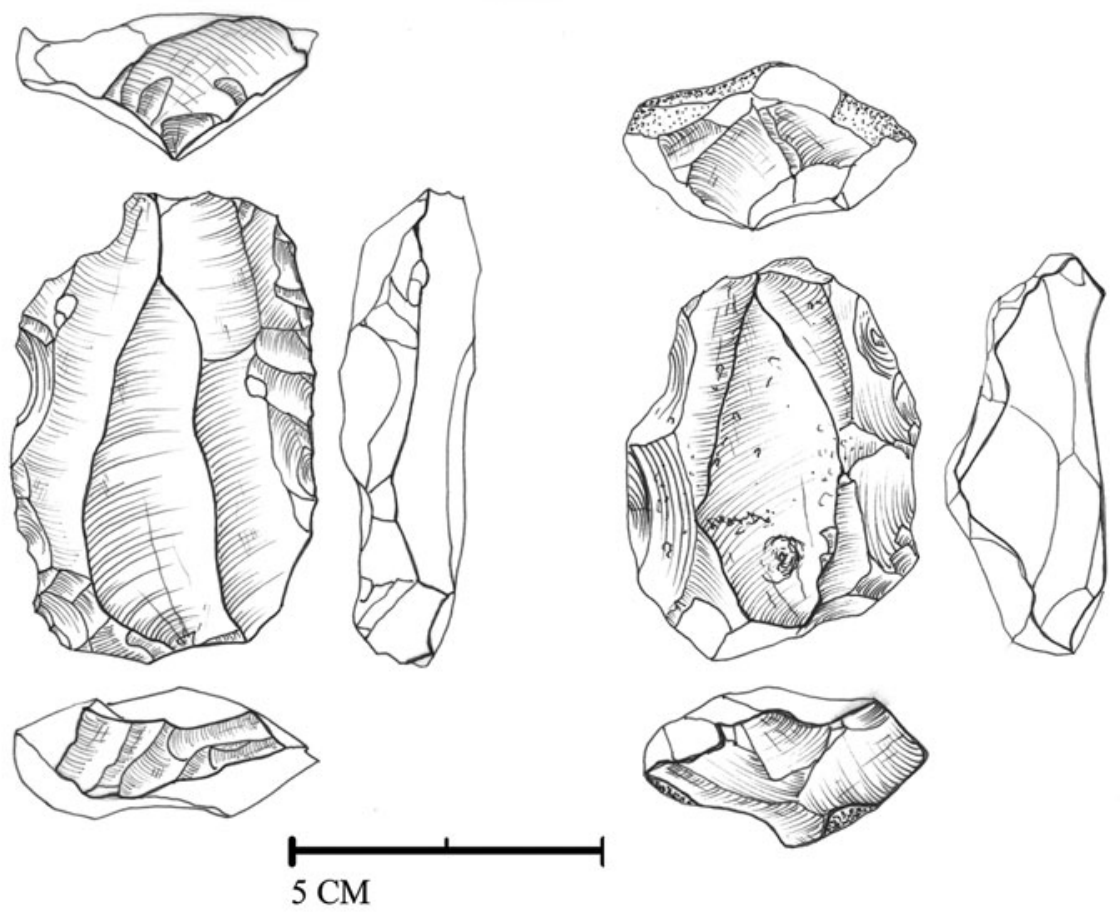

Figure 4. Nubian artefacts from Sufrat Dishsha.

\section{Acknowledgements}

We are grateful to the Omani Ministry of Heritage \& Culture. We would like to thank Naomi Martisius for English editing.

\section{References}

Bonilauri, S., T. Beuzen-Waller, J. Giraud, M. Lemée, G. Gernez \& E. Fouache. 2015. Occupation during the Lower and Middle/Late Palaeolithic period in the Sufrat Valley (Sultanate of Oman). Proceedings of the Seminar of Arabian Studies 45: 1-14.

Crassard, R. 2009. The Middle Paleolithic of Arabia: the view from the Hadramawt region, Yemen, in M.D. Petraglia \& J.I. Rose (ed.) The evolution of human populations in Arabia: paleoenvironments, prehistory and genetics: 151-68. Houten: Springer.

Guichard, J. \& G. Guichard. 1965. The Early and Middle Paleolithic of Nubia: a preliminary report, in F. Wendorf (ed.) Contributions to the prehistory of Nubia: 57-116. Dallas (TX): Fort Burgwin and Southern Methodist University Press.

(C) Antiquity Publications Ltd, 2017
Hilbert, Y.H., R. Crassard, G. Charloux \& R. LORETo. In press. Nubian technology in northern Arabia: impact on interregional variability of Middle Paleolithic industries. Quaternary International: 1-17.

Inizan, M.L. \& L. Ortlieb. 1987. Prehistoire dans la region de Shabwa au Yemen du sud. Paléorient 13: 5-22. https://doi.org/10.3406/paleo.1987.4414

Rose, J.I., V.I. UsiK, A.E. Marks, Y.H. Hilbert, C.S. Galletti, A. Parton, J.M. Geiling, V. Cerný, M.W. Morley \& R.G. Roberts. 2011. The Nubian Complex of Dhofar, Oman: an African Middle Stone Age industry in southern Arabia. PLoS ONE 6: e28239. https://doi.org/10.1371/journal.pone.0028239 
Usik, V.I., J.I. Rose, Y.H. Hilbert, P. Van Peer \& A.E. Marks. 2012. Nubian Complex reduction strategies in Dhofar, southern Oman. Quaternary International 300: 244-66. https://doi.org/10.1016/j.quaint.2012.08.2111

Van Peer, P. 2000. Makhadma 6, a Nubian complex site, in P.M. Vermeersch (ed.) Palaeolithic living sites in Upper and Middle Egypt: 91-103. Leuven: Leuven University Press.
Van Peer, P., P.M. Vermeersch \& E. Paulissen. 2010. Chert quarrying, lithic technology and a modern human burial at the palaeolithic site of Taramsa 1, upper Egypt. Leuven: Leuven University Press.

Vermeersch, P. 2010. The Middle Palaeolithic in the Egyptian Nile Valley, in E.A.A. Garcea (ed.) South-eastern Mediterranean peoples between 130,000 and 10,000 years ago: 66-88. Oxford: Oxbow. 